\title{
Regulatory Capital Planning and Deferred Tax Assets in a Post-Financial Crisis Environment
}

FLORIDA STATE UNIVERSITY

Evan M. Eastman, Anne C. Ehinger, and Cathryn M. Meegan

Florida State University \& Jacksonville University

Research Questions:

(1) Do insurers increase admitted DTAs

following the relaxation of admissibility rules?

(2) What are the implications of higher levels of DTAs?

\section{Motivation}

- Insurance regulators relaxed rules relating to DTA inclusion in regulatory capital

- DTAs are relatively illiquid compared to other assets

- Insurers represent a major part of the economy monitoring solvency is important
- Share of DTAs attributable to regulatory capital has been increasing over time for the life insurance industry, while total DTAs has not.
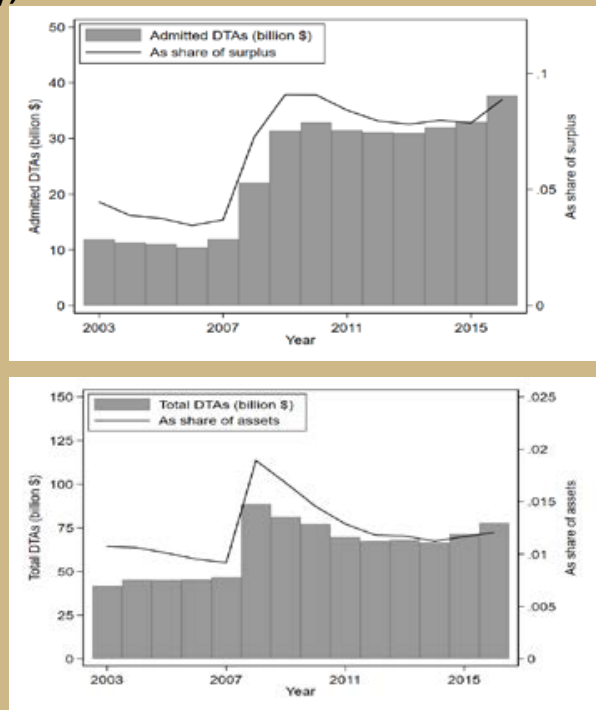

- $\quad$ Firms with relatively low regulatory capital tend to have a greater share of their regulatory capital composed of DTAs, suggesting that firms manipulate DTAs to appear financially healthier.

- The likelihood of insolvency increases with increased inclusion of DTAs in regulatory capital.

- Ratings agencies do not appear to discount high levels of reported DTAs.

\section{Contribution}

Our findings have important implications for regulators monitoring solvency in the insurance industry and those considering changes to capital standards for other financial institutions.

We appreciate valuable comments from:

- 2020 ATA Midyear Meeting \& Mike Mayberry

- 2020 WRIEC

- 2020 AAA Annual Meeting

- Texas A\&M Tax Readings Group

- The NAIC

- Mike Barth, Jeff Paterson, Dan Schwarcz 